\title{
Microcirugía parotídea
}

\section{Parotideal microsurgery}

Dr. Horst Muller

1. Posición del paciente: decúbito dorsal, occipucio descansa sobre la mesa operatoria, cabeza levemente inclinada al lado opuesto $\left(30^{\circ}\right)$.

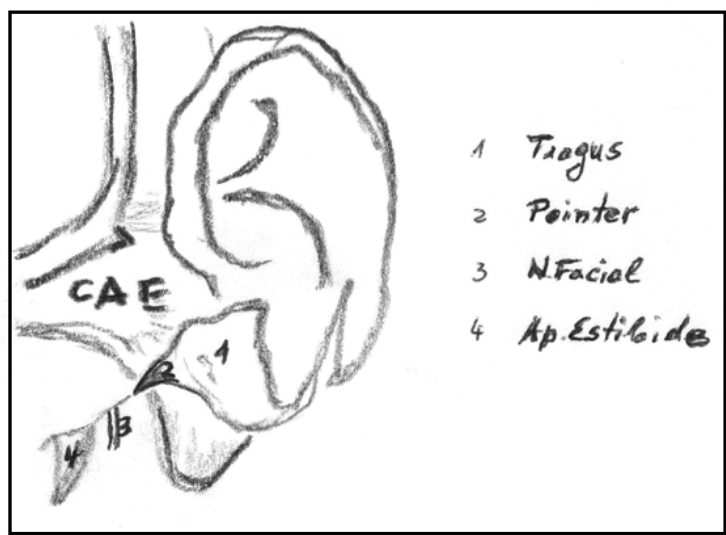

Figura 1.

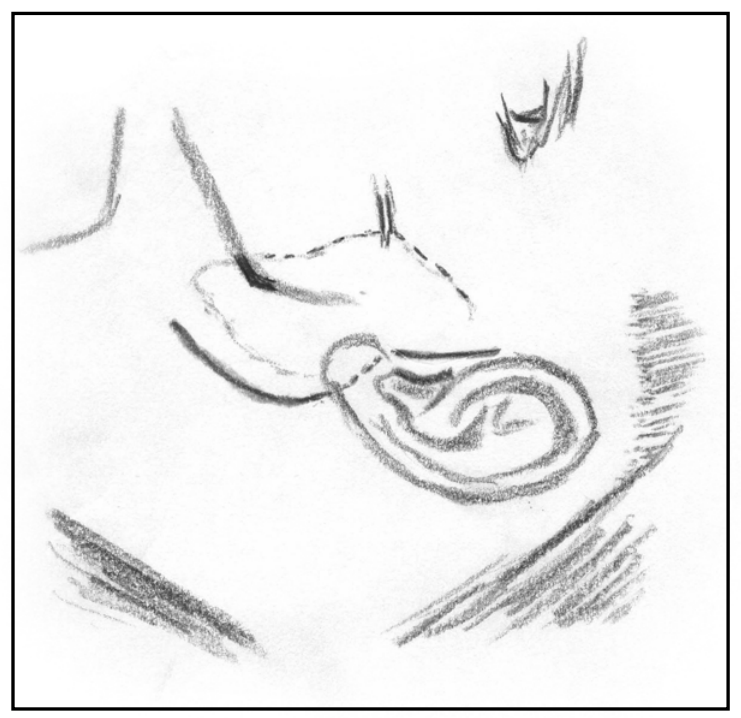

Figura 2.
2. Marcaciones en la piel de la cara (Figura2):

- Borde anterior de la glándula parotida.

- Dirección del Stennon $2 \mathrm{~cm}$ debajo del arco sigomático.

- Ángulo del maxilar inferior.

3. Infiltración subcutánea de $25-30 \mathrm{ml}$ de SF con 5 gotas (aguja de tuberculina) de adre nalina si no hay contraindicación por la zona de la incisión cutánea y debajo de la piel que será colgajo cutáneo, además un depósito de $2 \mathrm{ml}$ en la incisura tímpano mastoídea debajo del Pointer. Pointer es la prolongación interna del piso cartilaginoso del CAE (Figura 1).

4. Incisión de la piel con bisturí (Fgura 2), se profundiza con electro bisturí hasta la facia parotídea, hemostasia con bipolar.

5. Traccionando la piel con garrita de dos ganchos afilados se procede usando tijera de Metzenbaum a desarrollar el colgajo cutáneo, manteniéndose a ras de la facia parotídea hasta llegar al borde anterior de la parótida. No sobrepasar el borde anterior parotídeo para no dañar ramas periféricas del nervio facial. Dejar el colgajo de piel lo más grueso posible, para prevenir el desarrollo de la transpiración gustativa.

日 colgajo cutáneo se sutura a los paños, manteniendo orientación del Stennon y del ángulo de la mandíbula.

6. Liberación de la cápsula parotídea del tragus, mastoide, borde anterior del músculo ECM, dejando expuesto el Pointer y la incisura timpanomastoidea.

7. Bajo microscopio, con aumento menor, sin filtro y con ayuda del separador de oído angulado mosquito curvo fino, espátula de Freer, tijera puntiaguda, se va en búsqueda 


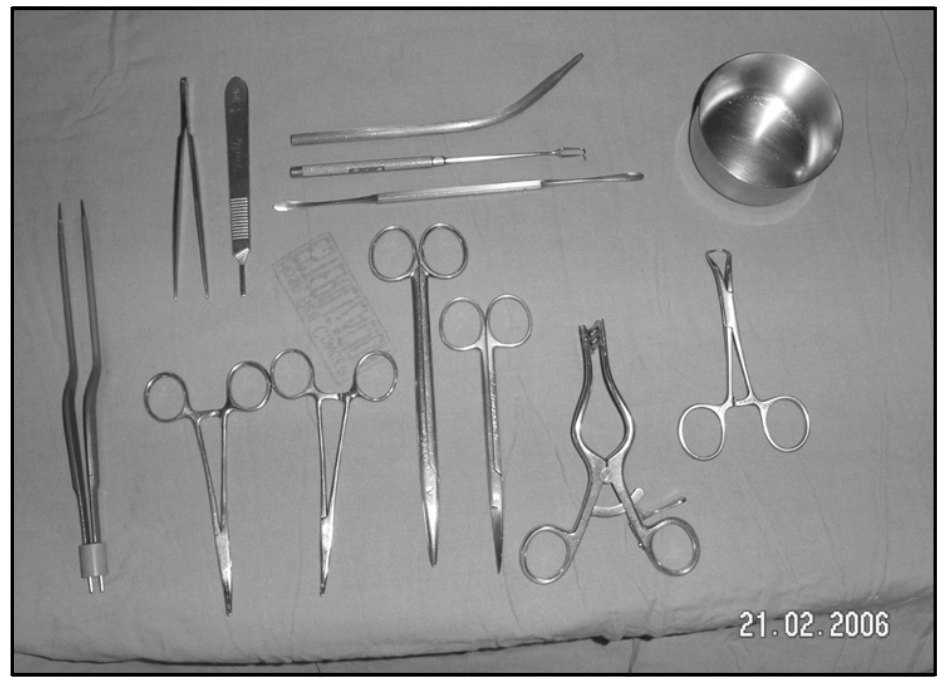

Figura 3.

del tronco del nervio facial. Hemostasia con bipolar pinza bayoneta fina.

日 microscopio se posiciona en dirección de la salida del tronco del NF. A unos $8 \mathrm{~mm}$ por dentro, debajo y delante del Pointer se supone que emerge el NF del agujero estilomastoideo, se dirige en un corto trayecto hacia abajo y adelante para luego superficializarse rápidamente en el cuerpo de la parótida.

8. Disección del nervio facial: con mosquito fino se separa el tejido sobre el nervio facial, la punta del mosquito se dirige siempre en dirección del filete nervioso, separando sus ramas y levantándolo se obtiene un túnel sobre el nervio facial que permite cortar el tejido glandular sin riesgo de dañar al nervio. 日 separador de oído permite mantener el campo operatorio despejado. $\mathrm{日}$ ayudante lo sostiene con leve tracción lateral, lo que facilita la labor del cirujano. Un aspirador especial con punta aplanada y dos orificios laterales permite controlar el sangramiento sin dañar al nervio. No tocar el nervio con compresa. Una vez expuesto completamente el nervio se elimina el tejido glandular con el tumor.

9. Luego se identifica al conducto de Stennon, doble ligadura con vicryl 3.0.

10. Lavado de la herida operatoria, hemostasia prolija.

11. Se instala Hemosuc Jackson-Pratt cuya sonda se saca por delante del extremo inferior de la incisión cutánea. Cierre por planos.

12. $日$ tiempo operatorio promedio es de 2,5 horas, puede extenderse a 4 horas.

Nota: antes de cerrar se realiza esquema o fotografía del nervio facial, útil en caso de reope ración. 